\title{
A atuação de Rodrigues Alves no Ministério da Fazenda (1891-1892 e 1894-1896)
}

\section{Rodrigues Alves' performance in the Ministry of Finance (1891-1892 and 1894-1896)}

Resumo: Francisco de Paula Rodrigues Alves, nascido em Guaratinguetá-SP em 1848, teve uma longeva carreira política, iniciada como deputado provincial e que teve como ápice as duas vezes em que foi eleito presidente da República. Em meio aos cargos eleitorais, ele teve duas passagens como Ministro da Fazenda (novembro de 1891 a agosto de 1892; novembro de 1894 a novembro de 1896). Em que pese a existência de uma historiografia sobre a vida e obra de Rodrigues Alves, ela pouco se debruçou sobre suas propostas e tentativas de ação quando ministro, tampouco fez o confronto destes aspectos com o debate econômico nacional do final do século XIX. Dessa forma, o artigo busca dar uma contribuição ao estudo da atuação ministerial de Rodrigues Alves, utilizando como base documental os Relatórios do Ministério da Fazenda para os anos de 1891, 1894 e 1895. Constata que o conservadorismo que Rodrigues Alves demonstrou desde os tempos de estudante o guiou na sua vida ministerial, expressando-se pela sua luta pelas finanças saudáveis do Estado.

Palavras-chave: Rodrigues Alves. Ministério. Fazenda. Conservadorismo.

Abstract: Francisco de Paula Rodrigues Alves, born in Guaratinguetá-SP in 1848, had a long political career, started as a provincial deputy and which culminated in the two times he was elected president of the Republic. In the midst of electoral posts, he had two stints as Minister of Finance (November 1891 to August 1892; November 1894 to November 1896). In spite of the existence of a historiography on the life and work of Rodrigues Alves, she did little to address his proposals and attempts at action as minister, nor did he confront these aspects with the national economic debate of the late 19th

\footnotetext{
* Doutor em Desenvolvimento Econômico - área de História Econômica - no Instituto de Economia da Universidade Estadual de Campinas (UNICAMP). Atualmente é ProfessorAssociado I no Departamento de Economia da Universidade Federal de São Carlos (UFSCar) campus Sorocaba-SP. Professor do Programa de Pós-Graduação em Economia da Universidade Federal de São Carlos, campus Sorocaba (PPGEc-So).
} 
Revista Brasileira de História \& Ciências Sociais - RBHCS

Vol. 13 No 26, Janeiro - Junho de 2021

century. Thus, the article seeks to make a contribution to the study of the ministerial work of Rodrigues Alves, using as a documentary base the Reports of the Ministry of Finance for the years 1891, 1894 and 1895. Notes that the conservatism that Rodrigues Alves has demonstrated since the times of student guided him in his ministerial life, expressing himself through his struggle for healthy state finances.

Keywords: Rodrigues Alves. Ministry. Finance. Conservatism.

\section{1 - Introdução}

A história de Rodrigues Alves entrelaça-se ao embate político desenhado no final do Brasil Império e na formação da Primeira República. Este paulista, nascido na cidade de Guaratinguetá em 1848 e que tornou-se bacharel pela Faculdade de Direito de São Paulo em 1870, foi eleito deputado provincial no ano seguinte, reeleito em 1874 e 1878 , eleito deputado geral - para a Corte do Império - em 1885, nomeado presidente da Província de São Paulo entre 18871888, eleito deputado constituinte por São Paulo em 1890, assumiu o Ministério da Fazenda de novembro de 1891 a agosto de 1892, eleito senador por São Paulo em 1893, tendo assumido novamente a pasta da Fazenda entre novembro de 1894 a novembro de 1896.

Na sequência, Rodrigues Alves foi reeleito senador federal em 1897, três anos depois elegeu-se governador do estado de São Paulo, cargo ao qual renunciou em 1902 para concorrer e ser eleito pela primeira vez à Presidência da República. Por fim, em 1912, ele foi reeleito ao governo do estado de São Paulo e, em 1918, o reconhecimento de sua obra política veio através da reeleição à presidência do Brasil em março daquele ano - feito único na Primeira República -, mandato que Rodrigues Alves não pôde cumprir, pois foi acometido pela gripe espanhola e faleceu na madrugada de 16 de janeiro de 1919 (Amaral e Franco, 2003; Faoro, 2000; Lang, 2016).

Conservador no Império, republicano de 16 de novembro de 1889 monarquistas que passaram a compor governo recém-criado - mas, sobretudo, Rodrigues Alves deve ser compreendido como um "[...] político até a medula dos ossos; político dos bancos da Faculdade de Direito ao leito de morte, na hora da morte" (Franco, 2000, p. 73). Neste sentido, suas escolhas e ações econômicas à frente do Ministério da Fazenda - em dois períodos (1891-1892 e 1894-1896) - 
estão enredadas no principal traço político que Rodrigues Alves seguiu precocemente e norteou toda a sua trajetória de deputado local à Presidência: a de um conservador, ou seja, de alguém que almeja a mudança social sem uma ruptura política, que entende a necessidade do progresso como base para o desenvolvimento, contudo, sem lastreá-lo tanto na revolução quanto no reacionarismo (Faoro, 2001) ${ }^{1}$.

A pugna entre as políticas econômicas neófitas - portanto, revolucionárias àquele momento - adotadas no início da República (1890-1891) vis-à-vis o ideário e as práticas conservadoras que sucederam-nas (1891-1892 e 1894-1896) serão o objeto de estudo deste capítulo. Colocados em lados opostos, as figuras de Rui Barbosa e Rodrigues Alves ilustram, respectivamente, as medidas de política econômica enquadradas pela historiografia econômica como revolucionárias/heterodoxas e, no outro espectro, as opções mais conservadoras/ortodoxas.

Através da análise desta dicotomia, que se evidenciava desde a década de 1860, quando os dois atores acima citados encontravam-se na Faculdade de Direito de São Paulo - formaram-se na mesma turma de 1870 - é que se clarifica as escolhas de Rodrigues Alves na pasta da Fazenda durante a década de 1890, sempre propalando a necessidade de corrigir os rumos financeiros equivocados iniciados pela passagem de Rui Barbosa no Ministério.

Este enquadramento busca se diferenciar das análises exclusivamente políticas da figura de Rodrigues Alves, que valorizaram sobretudo seus dois períodos presidenciais (Ricardo, 1951; Silva, 1939). Ademais, intentamos avançar em relação à grande obra de Afonso Arinos de Melo Franco (2001) que, lastreado no acesso aos arquivos de Rodrigues Alves, traça um grande panorama de toda a sua trajetória, apontando a importância da formação

\footnotetext{
1 "Conservador não se confunde com reacionário. O conservador não é o que busca trazer o passado de volta ou opor-se aos tempos novos, mas o que defende a herança material e cultural de um país, repele a revolução e aceita o progresso com a nota de desenvolvimento gradual do sistema político existente" (Rudolf Vierhaus, Conservantism, Dictionary of the History Ideas, New York, 1979 apud Faoro, 2001, p. 53). Em que pese Afonso Arinos (Franco, 2000, p. 120) ter denominado Rodrigues Alves como um "conservador progressista", entendemos que a união destes dois adjetivos - como aponta Bobbio, Matteucci e Pasquino (1998, p. 245) - pode olvidar que, no século XIX, mesmo que o Conservadorismo defendesse como fim o desenvolvimento da humanidade, que era uma pauta originalmente progressista, esta defesa se dava tendo como meio o fato de que tal desenvolvimento deveria se pautar no estoque de conhecimento e experiências pretéritas, ao contrário do que propalava o Progressismo, que visava a superação da dialética do passado. Portanto, em concordância com Bobbio, Matteucci e Pasquino, trataremos Rodrigues Alves como conservador.
} 
acadêmica e política que precedeu sua chegada à presidência da República². Em que pese o brilhantismo do texto de Afonso Arinos, pensamos ser necessário ajustar a análise que ele empreende sobre a passagem de Rodrigues Alves no Ministério da Fazenda.

Para tanto, buscamos eliminar uma certa hagiografia sobre suas ações ministeriais e encerrá-las no que era o debate sobre política monetária no Brasil Republicano, que opunha papelistas como Rui Barbosa versus metalistas, a exemplo de Rodrigues Alves, de acordo com a historiografia econômica. Como fontes primárias para o entendimento de seu agir econômico, utilizaremos os Relatórios do Ministério da Fazenda para os anos de 1891, 1894 e 1895, documentos que foram elaborados quando Rodrigues Alves estava à frente desta Pasta.

\section{2 - As origens familiares e a base acadêmica de Rodrigues Alves (1848-1870)}

Francisco de Paula Rodrigues Alves nasceu no dia 7 de julho de 1848, na fazenda do Pinheiro Velho, propriedade pertencente ao seu avô materno e localizada na cidade de Guaratinguetá, na porção paulista do Vale do Paraíba. Seu pai era o português Domingos Rodrigues Alves, que migrara ao Brasil em 1832, então com 14 anos de idade, e trabalhou inicialmente na Corte como comerciante na botica de Luís Manuel de Figueiredo - também português - até que, em 1837, mudou-se para Guaratinguetá3. Em 1843, Domingos casou-se com Isabel Perpétua de Marins, filha do mineiro Antonio José de Paula e Silva e de Maria Luísa dos Anjos Querido, de família da vila paulista de Cunha, onde parentes haviam participado da administração local. Antonio tinha o título de

\footnotetext{
2 Afonso Arinos de Melo Franco era casado com Ana Guilhermina Rodrigues Alves Pereira neta do Presidente da República - fato que lhe possibilitou ter acesso aos nove cadernos de notas e registros deixados por Rodrigues Alves (Franco, 2000, 74).

3 Em 1837, a vila de Guaratinguetá era uma localidade cuja economia apoiava-se na produção cafeeira, sendo a região do Vale do Paraíba responsável por 70\% do café produzido na província de São Paulo. Naquele momento, o Vale do Paraíba era região paulista em que mais celeremente se dava a transição dos canaviais aos cafezais, marcada dos cafeeiros e da própria população em vilas como Areias, Guaratinguetá, Jacareí, Lorena e Pindamonhangaba, localidades que, com suas fazendas, permitiam ao café superar em valor a produção de açúcar em São Paulo, em um decênio em que o café já se tornara o principal produto de exportação do Brasil (Luna e Klein, 2005, p. 88-112).
} 
alferes e possuía como uma de suas propriedades a fazenda do Pinheiro Velho (Amaral e Franco, 2003; Moura, 2002)4.

Do ponto de vista material, os relatos indicam que Rodrigues Alves teve uma infância tranquila que se dividia entre estar na casa comandada pelo pai que era comerciante e também se tornaria fazendeiro - e situada no centro de Guaratinguetá e, por inúmeras vezes, fazer estada na fazenda do avô. Esta rotina foi quebrada em 1859 quando, depois de ter realizado os estudos primários nesta cidade, o pequeno Francisco de Paula foi enviado para a Corte para estudar no Colégio Pedro II, criado em 1838 e à época era a principal instituição de ensino secundário no Brasil (Franco, 2000; Lang, 2016; Carvalho, 2007).

O tempo em que estudou no Pedro II ficou marcado para Rodrigues Alves em dois aspectos: seu elevado desempenho individual no colégio e o círculo de amizades com pessoas que moldariam o futuro político do Brasil - assim como ele. Sobre o primeiro item, o colégio se notabilizava pelo rigor no ensino e a premiação aos melhores discentes de cada ano, posto que Rodrigues Alves alcançou nos anos de 1859, 1860, 1862, 1864 e 1865 - em 1861 e 1863 ele ficou no segundo lugar. De outra parte, o Pedro II tinha como uma de suas funções uniformizar a formação da elite imperial, o que atraía aos seus bancos filhos de famílias abastadas economicamente e influentes na esfera política, tendo como exemplo Joaquim Nabuco, colega de turma que se formou bacharel em Letras no ano de 1865, junto com Rodrigues Alves (Carvalho, 2007; Amaral e Franco, 2003).

O caminho natural para os filhos de famílias com recursos, uma vez formados no colégio Pedro II, era ingressar ao ensino superior em uma das diversas universidades europeias - como Coimbra (Portugal) - ou nas poucas escolas do Império voltadas ao ensino superior, como as Escolas de Direito criadas em 1827: em São Paulo e a de Olinda que, em 1854, seria transferida ao Recife. Estas duas instituições cobravam anuidades e voltavam-se à geração da elite política imperial, ofertando cursos que duravam cinco anos e em que constavam disciplinas como Economia Política, Direito Mercantil e Marítimo. O objetivo era ir além da formação de juristas, mas contribuir ao Império com

\footnotetext{
4 No exército brasileiro, alferes é uma antiga patente de oficial abaixo de tenente.
} 
indivíduos aptos a serem advogados, deputados, senadores, diplomatas e demais cargos de relevância no aparelho de Estado (Carvalho, 2007)5.

A 5 de março de 1866, Rodrigues Alves ingressou na Escola de Direito de São Paulo (atual Faculdade do Largo do São Francisco, pertencente à Universidade de São Paulo) e, segundo Afonso Arinos (2001, p. 94), passou a compor a "[...] turma mais gloriosa que jamais cursou qualquer faculdade de direito brasileira”. Os nomes são descritos por José Murilo de Carvalho:

A turma de 1866 da escola de São Paulo incluía Castro Alves, o
poeta abolicionista e de tendências republicanas; Joaquim
Nabuco, futuro deputado, líder abolicionista e monarquista
convicto; Afonso Pena, futuro ministro no Império e Presidente
da República; Rui Barbosa, futuro deputado no Império, líder
liberal e ministro republicano; Rodrigues Alves, futuro
deputado no Império e depois Presidente da República, e Bias
Fortes, um dos principais políticos de Minas Gerais na
República (Carvalho, 2007, p. 83). O período em que esteve na Escola de Direito, entre março de 1866 até sua formatura em novembro de 1870, proporcionou a base acadêmica e os primeiros traços políticos que norteariam a carreira de Rodrigues Alves ${ }^{6}$. Internamente, a Escola traduzia a divisão política que se estabelecera no Império durante a década de 1840: conservadores versus liberais7. Diante desta dicotomia, os estudantes dividiam-se em órgãos que defendiam um dos lados: Rodrigues Alves pertenceu ao jornal conservador Imprensa Acadêmica, enquanto liberais, como Rui Barbosa, integravam o Radical Paulistano (Franco, 2000).

Em 1870, por ocasião de se proceder à eleição de redator-chefe da Imprensa Acadêmica, a Academia dividiu-se em 'liberais' e 'conservadores', pleiteando as candidaturas de Afonso Pena,

\footnotetext{
5 A elite política do Brasil Império era altamente educada, pois no período de $1822-1889$, $91 \%$ dos ministros possuíam curso superior e, no mesmo período, $76 \%$ do senadores e deputados. Estes dados indicam o abismo educacional que havia com o restante da população, uma vez que no Brasil, em 1872, 82\% das pessoas de 5 anos ou mais eram analfabetas (Carvalho, 2007, p. 78; Ferraro e Kreidlow, 2004, p. 182).

6 As avaliações nas disciplinas do curso de Direito baseavam-se em dissertações escritas e defendidas pelos estudantes. Das sete dissertações que foram defendidas por Rodrigues Alves, somente duas foram descritas por Afonso Arinos, sendo uma sobre Direito Natural em que aborda a natureza do Estado e se há a possibilidade de se exercer o direito sem sua existência, utilizando autores como Kant, Rousseau e Hobbes. A outra dissertação trata da obrigatoriedade da proposição das ações em juízo. Diante disso, entendemos que a visão econômica que Rodrigues Alves apresentará no Ministério da Fazenda não é uma consequência de ideias econômicas defendidas nos tempos de faculdade, mas é decorrência da posição política que ele apresentou naqueles anos, posições estas de cunho conservador como veremos.

7 Do ponto de vista ideológico, o partido conservador defendia a centralização, era refratário às reformas, apoiava o Conselho de Estado, o poder moderador sem a tutela dos ministros e onipresença do Imperador. Por sua vez, os liberais, muitas vezes em contradição ao governo, eram partidários da descentralização, do senado eletivo, da soberania popular e favorável ao fim do poder moderador (Faoro, 2000, p. 365).
} 
liberal, e Rodrigues Alves, conservador. O pleito foi renhido. Houve empate no resultado e a Academia resolveu que, naquele ano, os redatores seriam os dois eleitos. Recordo-me de que fiquei muito desapontado. Os conservadores estavam, na Academia, em evidente minoria. Seria um despropósito fazer questão política da eleição e o empate se deu por que grande número de acadêmicos liberais aceitaram o meu nome (Depoimento de Rodrigues Alves apud Franco, 2000, p. 99).

Entretanto, havia uma organização engendrada dentro da Faculdade de Direito de São Paulo em que as diferenças entre conservadores e liberais se esvaíam: a Burschenschaft ou, como ficou conhecida, a Bucha Paulista. Criada por volta do ano de 1834 pelo alemão Julio Frank, que era professor na Faculdade, a Bucha era uma sociedade com finalidades assistenciais, que buscava auxiliar financeiramente estudantes para que se mantivessem na Escola. Como uma sociedade secreta, seus membros - os bucheiros - eram escolhidos com base no desempenho acadêmico e na suposição de serem os de caráter mais reto (Lang, 2016; Santos, 2000).

A Bucha se assumia como uma sociedade de cunho liberal, abolicionista e republicana. Porém, a presença de membros como Rodrigues Alves - que era conservador, escravista e monarquista - indica que os laços entre os bucheiros eram mais robustos que suas diferenças políticas. Esta superação das querelas se mostrou fundamental ao papel futuro que os bucheiros desempenharam na Primeira República, quando liberais e conservadores se converteram em republicanos, vários deles membros da Bucha, bacharéis que em conjunto passaram a comandar a vida política do Brasil (Santos, 2000).

Com efeito, seus dirigentes [da Bucha], daí por diante, em diversos postos, chamaram-se Francisco Otaviano, Visconde de Ouro Preto, Rui Barbosa, Assis Brasil, Rodrigues Alves, Afonso Pena, Barão do Rio Branco, Pinheiro Machado, Campos Sales, João Pinheiro, Afonso Ari nos, Pedro Lessa, Venceslau Brás, Bernardino de Campos, Davi Campista, Washington Luís, Melo Franco, Antônio Carlos, Altino Arantes, Artur Bernardes, Vergueiro Steidel, Macedo Soares e numerosíssimos outros vultos preeminentes do Direito, das letras e da política imperial e republicana (Franco, 2000, p. 106).

Ao formar-se bacharel em Direito no dia 5 de novembro de 1870, Francisco de Paula Rodrigues Alves reunia um elevado desempenho acadêmico, um rol de amizades e laços de confiança com figuras-chave no desenrolar futuro da política nacional e, não menos importante, a convicção de que as ideias conservadoras seriam sua diretriz na ação política e, consequentemente, na 
seara econômica ${ }^{8}$. No mesmo dia, o jornal Opinião Conservadora estampava o seguinte vaticínio sobre o jovem que havia sido um colaborador do periódico “Caráter sisudo, inteligência cultivada, ideias sãs são elementos valiosíssimos que o Sr. Rodrigues Alves porá a serviço da pátria, se quiser dedicar-se à carreira política” (Franco, 2000, p. 113).

\section{3 - O início da trajetória política de Rodrigues Alves (1871-1889)}

Uma vez graduado como bacharel em Direito, Rodrigues Alves retornou à Guaratinguetá onde foi nomeado ao cargo de promotor interino a $11 \mathrm{de}$ dezembro de 1870. Entretanto, a política logo concentraria sua atenção, pois, em janeiro de 1872, ele assumia o cargo de deputado provincial - o equivalente a deputado estadual. Sua eleição se deu pelo Partido Conservador, ao qual se filiara ainda nos tempos da faculdade, e, também, escorando-se nos laços de parentesco com o Visconde de Guaratinguetá, cuja neta Ana Guilhermina de Oliveira Borges casou-se com Rodrigues Alves em setembro de 1875. Doravante, a política seria o mote de sua vida profissional (Amaral e Franco, 2003; Lang, 2016)9.

Na década de 1870, Rodrigues Alves, apoiado pela parentela do Visconde, seria reeleito em Guaratinguetá para o cargo de deputado provincial em 1874 e 1878, sempre pelo Partido Conservador. Nas poucas vezes em que subiu à tribuna abordou temas como a escassez de crédito e mão-de-obra à lavoura, o que era uma crítica geral dos cafeicultores paulistas no período. Como um homem do Partido, defendia a bandeira conservadora da emancipação dos escravos, mas de maneira moderada, por exemplo, ao se colocar contra a cobrança de um imposto provincial sobre os cativos, o que acarretaria um aumento nos custos da agricultura cafeeira (Franco, 2000; Queiroz, 2006; Salles, 2009).

\footnotetext{
8 Rodrigues Alves foi o escolhido da turma para, no dia 25 de abril de 1870, proferir o discurso que saudou a volta dos Voluntários Paulistas que haviam lutado na Guerra do Paraguai (18641870) (Franco, 2000, p. 79).

9 Como o fio condutor é a atuação política de Rodrigues Alves, sobretudo no Ministério da Fazenda, não enfatizaremos outras atividades profissionais que ele teve no âmbito privado. Todavia, é importante mencionar que em 1873 foi nomeado juiz municipal e primeiro substituto do juiz de direito da comarca de Guaratinguetá. Em 1876-1877, associou-se à sogra e ao irmão Virgílio para explorar a fazenda de café Três Barras e abriu a firma Viúva Borges e Genros. Com o início da decadência da produção cafeeira na região, junto com o irmão abriu as fazendas São Manoel, Santa Ana e Santa Maria, entre os municípios de Jaú e Bauru, e criou a firma Rodrigues Alves e Irmão (Lang, 2016).
} 
O destaque nesta primeira passagem de Rodrigues Alves pela Assembleia Provincial de São Paulo deu-se a partir de março de 1873, quando ele se dirigiu à tribuna para debater seu projeto de tornar obrigatório o ensino primário na Província. Em que pese, o Ato Adicional de 1834 ter alocado às Províncias a atribuição sobre o ensino primário, o que se notava em São Paulo era que as vilas e cidades tinham que pleitear a instalação de escolas, negociação política que era complicada e tornou-se uma das causas fundamentais da Província ter um índice de matrículas menor que a média nacional na metade do século XIX (Colistete, 2017). Neste sentido, o projeto de Rodrigues Alves, ao trazer como exemplo propostas semelhantes que haviam sido aprovadas na Alemanha, Portugal e França - apesar de críticas que o acusavam de ser socialista - foi apoiado por outros parlamentares e aprovado a fevereiro de 1874 (Amaral e Franco, 2000).

Após afastar-se da seara política no interregno 1880-1884, Rodrigues Alves é eleito, em dezembro de 1884, para o cargo de deputado geral equivalente ao deputado federal - a representar São Paulo na Câmara Imperial. No decênio, a grande questão nacional era a abolição da escravatura e, como membro do Partido Conservador e fazendeiro do Vale do Paraíba - região em que o braço escravo ainda era a principal fonte de mão-de-obra - Rodrigues Alves se posicionou na tribuna de maneira contrária ao projeto iniciado no ano anterior de libertação dos escravos com 60 anos ou mais - a Lei dos Sexagenários, que seria aprovada em setembro de 1885. Rodrigues Alves, acompanhado inclusive de membros do Partido Republicano Paulista - criado em 1873 - alegava os eventuais distúrbios na ordem que a libertação poderia causar, além da inviolabilidade da propriedade privada, neste caso, os cativos (Schulz, 2013; Costa, 1998; Amaral e Franco, 2003).

A questão abolicionista era o grande tema nacional e provincial que novamente demandaria todos os esforços e atenção de Rodrigues Alves quando, em 8 de novembro de 1887, ele foi nomeado ao cargo de Presidente da Província de São Paulo - equivalente a governador do Estado. A nomeação se deu quando João Maurício Wanderley (Barão de Cotegipe), membro do Partido Conservador, era presidente do Conselho de Ministros do Império, no qual Antonio da Silva Prado - importante cafeicultor, empresário e político - era o responsável pela pasta da Agricultura, Comércio e Obras Públicas. De uma 
parte, a escolha de Rodrigues Alves para comandar a província de São Paulo vinha lastreada pela trajetória no Partido Conservador e a defesa de seu ideário na Assembleia Provincial e na Câmara. Por outro lado, Antonio Prado criara em 1881 a União Conservadora, uma ala dissidente que buscava aglutinar os jovens paulistas do Partido e fazer frente ao avanço do Partido Liberal na Província, sendo que Rodrigues Alves aderira ao movimento desde o início (Franco, 2000).

Os dois relatórios que o presidente da Província apresenta à Assembleia Provincial - o primeiro a 10 de janeiro de 1888 para o início dos trabalhos da Assembleia e o segundo a 27 de abril de 1888 quando ele solicitou demissão em solidariedade à queda do Gabinete Cotegipe - expõe a gravidade do momento de transição em que a economia e a sociedade paulista se encontravam. Os relatos constantes de fugas de cativos das fazendas demandavam ações peremptórias das forças de segurança na tentativa de capturar os fugidios. Entre a busca pela liberdade encetada pelo movimento abolicionista na década de 1880, e a manutenção da ordem pública e o restabelecimento da propriedade privada, Rodrigues Alves se posiciona junto ao ideário comum dos políticos paulistas de então ${ }^{10}$.

Não vos são estranhas as dificuldades que encontrei ao iniciar a minha administração e os graves acontecimentos que sucederam, consumindo todos os meus esforços a preocupação de assegurar a ordem pública, ameaçada em vários pontos da Província.

A propaganda pacifica em favor da emancipação dos escravos, inspirada nos sentimentos de humanidade e patriotismo, desperta em todos os espíritos manifestações de franca adesão.

A liberdade, que surge sem a desordem, sem a desorganização do trabalho ou o tumulto das leis econômicas, é uma aspiração nobilíssima, a que o espírito público tem-se habituado em todas as zonas do País (São Paulo, 1888a, p. 7; grifos meus).

Para debelar a desordem, resolver a questão da mão-de-obra e sustentar a atividade produtiva na Província, Rodrigues Alves advogava uma transformação no trabalho, que inclusive ele já defendera anteriormente quando deputado, que era a maciça entrada de imigrantes. Dada a urgência do momento, uma de suas primeiras medidas quando da reabertura dos trabalhos na Assembleia

10 "O PRP só apoiou abertamente a abolição um ano antes de sua efetivação, na mesma época em que o Partido Conservador de São Paulo, liderado por Antonio Prado, tomou decisão semelhante" (Carvalho, 2007, p. 215). A corroborar esta citação de José Murilo de Carvalho temos o relato do próprio Rodrigues Alves sobre uma reunião de grandes fazendeiros na cidade de São Paulo, a 15 de dezembro de 1887, que visava direcionar o movimento abolicionista, pressupondo o fim da escravidão em prazo de três anos (São Paulo, 1888b, p. 23). 
Provincial foi, a 3 de fevereiro de 1888, aprovar a lei $\mathrm{n}^{0} 1$ que autorizava $o$ estabelecimento de contrato com a Sociedade Promotora da Imigração (SPI) ${ }^{11}$ para viabilizar a chegada de 100 mil imigrantes, sendo que, 60 mil deveriam desembarcar em Santos até o final do ano (São Paulo, 1888a; São Paulo, $1888 \mathrm{~b})^{12}$.

O custo desta operação imigratória, pois as despesas da viagem eram financiadas pelo governo paulista, atingiam tal monta que Rodrigues Alves dizia no relatório aos deputados que "Conheceis os grandes sacrifícios que temos feito com o serviço da imigração" (São Paulo, 1988b, p. 84). Para o exercício fiscal de julho de 1888 a junho de 1889, o Orçamento Provincial previa um saldo a favor de 515 contos de réis, porém, para o mesmo exercício, os dispêndios com a imigração chegariam a 2.400 contos, déficit que, do ponto de vista orçamentário, justificava-se apenas pelo fato do serviço da imigração não compor as despesas ordinárias do orçamento, sendo financiado por empréstimos e créditos extraordinários (São Paulo, 1888a; São Paulo, 1888b).

O período de Rodrigues Alves à frente do governo da província de São Paulo foi abreviado pela queda do Barão de Cotegipe - contrário à abolição da escravatura - que, pressionado pela decisão do Exército de não capturar escravos fugitivos e, também, pelas dificuldades de seu relacionamento com a Princesa Isabel, renunciou a 7 de março de 1888 - foi substituído por João Alfredo Correia de Oliveira, também do Partido Conservador. Em solidariedade, Rodrigues Alves apresentou sua demissão três dias depois e reassumiu o cargo de deputado geral no Rio de Janeiro, em meio aos debates sobre o fim da escravidão. A 13 de maio, ele foi um dos 83 deputados que votaram favoravelmente à Abolição - apenas 9 foram contrários - fruto do ambiente que já fora açambarcado pelo movimento abolicionista que conseguiu convencer até membros do Partido Conservador (Carvalho, 2007; Lang, 2016).

\footnotetext{
${ }^{11}$ Em julho de 1886 foi criada a Sociedade Promotora da Imigração (SPI), instituição presidida por Martinho Prado Junior e que contava com outros fazendeiros e empresários ligados ao café. A atuação da SPI, em associação com o governo de São Paulo, dava-se através de agências na Europa que recrutavam trabalhadores e subvencionavam seus custos de viagem até o Brasil, com vistas a abastecer as lavouras cafeeiras com trabalhadores assalariados (Kugelmas, 1986).

12 Para se ter uma ideia do volume de pessoas que chegariam a partir daquele momento, pontuamos que entre 1877-1887, desembarcaram no porto de Santos 69.863 imigrantes e, entre 1888-1898, esta cifra atingiu a marca de 717.794 pessoas, principalmente composta de italianos (Rocha, 2007, p. 74).
} 
Há muitos anos, foi em novembro de 1887 , coube-me a honra de presidir pela primeira vez a antiga Província de São Paulo [...] Agitava-se, naquele tempo, a questão abolicionista, e os chefes do Partido Conservador, ao qual pertencia, estavam em divergência quanto ao modo de ser resolvido o momentoso problema [...] $\mathrm{Eu}$ mesmo fui envolvido no movimento e dominado pela propaganda, concorrendo com o meu voto, na Câmara dos Deputados, para que fosse aprovada a lei que aboliu o elemento servil (Discurso Rodrigues Alves, 1916 apud Franco, 2000, p. 153).

Sem a base escravista, o Império sustentou-se por mais 18 meses, até a República ser proclamada a 15 de novembro de 1889 (Holanda, 2008). Neste ínterim, o deputado geral Rodrigues Alves, que mantinha o hábito de ser pouco eloquente à tribuna, foi colocado na Comissão de Orçamento, em que seria o relator. Se, no Império, o egresso de Guaratinguetá não conseguira extravasar sua ascendência fora das hostes paulistas, bem diferente eram os rumos que o aguardavam na Primeira República.

\section{4 - O político na Fazenda: as duas passagens do ministro Rodrigues Alves (1891-1892 e 1894-1896)}

Proclamada a República, após o golpe civil-militar de 15 de novembro de 1889, instalava-se o governo provisório do marechal Deodoro da Fonseca. Um dos principais nomes a compor a nova equipe ministerial seria o jurista Rui Barbosa, nomeado Ministro da Fazenda (Mattos, 2012).

$\mathrm{Na}$ seara econômica, a grande questão que se colocava era a de uma economia que ainda se encontrava na transição de um modelo escravista para a predominância do trabalho assalariado. Para tanto, a demanda por papelmoeda tenderia a aumentar, considerando um elemento novo que era necessidade de pagamento de salários a uma maior massa de trabalhadores algo inexistente à condição de escravo (Franco, 1989; Schulz, 2013).

Expandir, ou não, o meio circulante era uma decisão que haveria de considerar o compromisso que o Brasil assumiu em 1846, ao definir o valor da moeda nacional (mil-réis) frente à moeda inglesa (libra esterlina), na paridade de 27 pence por mil-réis. Esta adesão marcava o atrelamento da economia brasileira ao sistema monetário vigente da segunda metade do século XIX até a I Guerra Mundial, o Sistema do Padrão-Ouro. A pedra angular dos sistema era que cada país deveria definir a cotação de sua moeda frente ao metal 
(preferencialmente o ouro) - como no caso da moeda inglesa - ou à moeda de referência que era a libra esterlina - caso do Brasil - dada a centralidade do Reino Unido na produção, comércio e finança internacional. Uma vez definida a cotação, o sistema se sustentava no compromisso tácito da autoridade monetária de cada nação em perseguir esta paridade, pois o conhecimento prévio sobre o valor da unidade monetária de cada país tenderia a facilitar os fluxos internacionais de produção e capitais (Franco e Lago, 2012; Eichengreen, 2000).

Havia um consenso entre os formuladores de política econômica no final do Império e início da República sobre a necessidade de expandir a emissão monetária frente à transição a uma economia assalariada ${ }^{13}$. Este consenso se apoiava na conjuntura econômica dos anos 1888-1889, que demonstrava os maiores saldos na balança de pagamentos do Brasil - sobretudo devido à liderança nas exportações mundiais de café e borracha e à grande entrada de capital estrangeiro no biênio. Portanto, considerando que ao pensamento econômico do século XIX, o que garantia o papel-moeda emitido era o equivalente em metal guardado nos cofres bancários, abria-se uma oportunidade de expandir o meio circulante quando ao par com um maior ingresso de metais preciosos na economia brasileira (Franco, 1988; Singer, 2006).

Todavia, qual seria o nível ótimo para se expandir a moeda? Esta questão colocava em polos opostos papelistas e metalistas. Do lado heterodoxo situavam-se os papelistas que, discursando a necessidade de bancos e crédito à uma economia em transição, admitiam um relaxamento nas regras de emissão monetária, que poderiam contemplar, em alguns casos, a emissão de papelmoeda sem lastro, permitindo uma redução nas taxas de juro que fomentariam os investimentos. Já do lado ortodoxo, os metalistas, calcados nas regras do sistema monetário do padrão-ouro e confiando na taxa de câmbio, eram defensores da conversibilidade da moeda, o que limitava as emissões à existência de lastro metálico, denunciando os malefícios do excesso monetário

13 O próprio Leopoldo de Bulhões, que seria o ministro da Fazenda responsável pelo plano contracionista do Funding Loan (1898) admitiria em 1893 que era necessário expandir o dinheiro em circulação de 200 mil contos de réis para um patamar entre 250 e 300 mil contos (Schulz, 20113, p. 190). 
que redundavam na desvalorização do câmbio e inflação (Fonseca e Mollo, 2012, p. 215-218).

De modo geral, o campo metalista - nomes como Francisco Belizário, Torres Homem e Joaquim Murtinho - teve maior êxito no tempo imperial, calcando-se no fato de apoiar seu discurso no que era a teoria econômica vigente na Inglaterra. O resultado deste predomínio, de uma parte, foi uma taxa de câmbio que não variou tanto na média desde 1846 - ficando no intervalo entre 20 e 27 pence por mil réis ${ }^{14}$. Entretanto, segundo Celso Furtado (2000, p. 175) "O sistema monetário de que dispunha o país demonstrava ser totalmente inadequado para uma economia baseada no trabalho assalariado", pois a massa monetária em circulação - algo em torno de 200 mil contos de réis em 1889 teria diminuído entre 1880 e 1889 . Ademais, o crédito era caro e o sistema bancário concentrado no Rio de Janeiro (Franco, 1989; Fonseca e Mollo, 2012).

A chegada de Rui Barbosa - um papelista assim como Souza Franco, Barão de Mauá, Visconde de Ouro Preto - marcaria uma guinada na política monetária nacional ajustando-a ao ideário papelista que, por sua vez, apontava a experiência estadunidense - com seu sistema de bancos pulverizados pelo país - como modelo. No dia 17 de janeiro, o ministro instituiu a lei bancária de 1890, criando três novos bancos de emissão (Norte, Centro e Nordeste), que foram autorizados a emitir até 450 mil contos de réis - valor que representava mais que o dobro do papel-moeda em circulação naquele momento - em papéis que seriam inconversíveis e lastreados em apólices da dívida pública. Junto à lei bancária e no intuito de canalizar a expansão creditícia à constituição de novas firmas, Rui Barbosa instituiu os decretos $\mathrm{n}^{0} 164$ e 165, também em 17 de janeiro de 1890, que facilitavam a formação de sociedades anônimas, pois possibilitavam a estas empresas negociar suas ações apenas com a integralização de $10 \%$ do capital subscrito pelos incorporadores - antes eram necessários subscrever 20\% do capital (Levy, 1977; Levy, 1994; Franco, 1989; Marcondes e Hanley, 2010; Tannuri, 1981).

${ }^{14}$ Fonseca e Mollo (2012) demonstram que o debate sobre a emissão da moeda e seus efeitos se originara na Inglaterra da segunda metade do século XVIII e opunha do lado ortodoxo a currency school - defensores de um controle maior sobre a oferta monetária e apoiados nos escritos de David Ricardo - versus a banking school - que pregava uma liberdade maior da emissão e dos agentes emissores. Transferida ao Brasil, esta disputa se fez entre metalistas e papelistas. 
Os efeitos desta nova diretriz da política econômica brasileira foram sentidos ainda em 1890. Em outubro daquele ano, o Governo Federal se mostra preocupado com o volume das novas emissões, que haviam majorado $40 \% \mathrm{em}$ relação ao estoque de papel-moeda emitido a janeiro de 1890 . A praça comercial da cidade do Rio de Janeiro era palco da formação incessante de novas empresas, em uma especulação bursátil que visava registrar a firma, lançar seus papéis ao público na Bolsa e lucrar com a venda das ações - apenas no ano de 1891 formaram-se 313 novas empresas na capital federal. Várias destas firmas eram empresas de fachada, mas que passaram a compor o ativos dos bancos emissores e servirem de lastro aos seus empréstimos junto ao Governo, envolvendo o sistema bancário na crise que ficou conhecida como Encilhamento - em referência às apostas nas corridas de cavalo à época (Franco, 1989; Calógeras, 1960).

O final do ano 1890, quando se consolidara a crise do Encilhamento, ainda teria a ocorrência de uma crise no cenário externo, devido às dificuldades do banco inglês Baring junto à Argentina, que gerou uma diminuição nos fluxos de capital estrangeiro que aportavam ao Brasil (Franco e Lago, 2012, p. 186)15. Rui Barbosa saiu da pasta da Fazenda em janeiro de 1891 e o legado de seu período à frente do ministério - que não foi revertido pelo seu sucessor, o Barão de Lucena - na visão de seus críticos contemporâneos e recentes, seria a desvalorização cambial, o excesso de moeda e uma crise especulativa gerada pela formação de empresas frágeis na Bolsa de Valores do Rio de Janeiro firmas que entrariam em falência nos anos posteriores - efeitos imputados a uma suposta irresponsabilidade de Rui na condução das medidas econômicas (Taunay, 1923; Almeida e Croce, 2016; Furtado, 2000; Triner e Wandschneider, 2005; Triner, 2014; Schulz, 2013; Passananti e Gerber, 2015) ${ }^{16}$.

\footnotetext{
${ }^{15}$ A dificuldade na venda dos papéis da Sociedade de Água e Esgoto de Buenos Aires foi o estopim da crise do banco Baring no mercado londrino em novembro de 1890 (Lenz, 2010, p. 229). Triner e Wandschneider (2005, p. 208-222) demonstram que, a partir daquele mês, houve aumento no prêmio de risco dos títulos soberanos do Brasil em Londres, indicando um contágio da crise argentina sobre o Brasil dado pela subida do custo de captação de recursos junto a Londres que, de modo geral, diminuiu na década de 1890.

16 Há trabalhos na historiografia econômica que tentam mostrar que os fenômenos que marcaram o Encilhamento não se devem unicamente às medidas de Rui Barbosa, pois devem considerar os efeitos da retração do capital estrangeiro com a crise Baring (Franco e Lago, 2012). Ademais, vários textos apontam que a expansão das emissões teriam favorecido à formação de empresas, sobretudo no ramo industrial, marcando um primeiro avanço expressivo do crescimento manufatureiro no Brasil (Suzigan, 2000; Stein, 1979; Fishlow, 1972; Lobo, 1976; Versiani, 1980).
} 
Os membros do Partido Republicano Paulista (PRP), que expressavam os interesses do grupo dominante no complexo econômico cafeeiro do estado de São Paulo, demonstravam-se insatisfeitos com a desordem na vida econômica e política da República, principalmente após Deodoro da Fonseca fechar o Congresso Nacional a 3 de novembro de 1891. A resposta por parte do PRP veio em uma aliança com militares oposicionistas que, a 23 de novembro, forçaram Deodoro a entregar a presidência e, em seu lugar, assumiu o vice-presidente, o marechal Floriano Peixoto. Naquele momento, a oferta total de moeda alcançara 513 mil contos, uma majoração de $148 \%$ em relação a dezembro de 1889. Já a taxa de câmbio que, há dois anos, estava no patamar de 27 pence por mil réis, havia se desvalorizado para 13 pence, fato que encarecia a importação de bens básicos, como o trigo, de insumos às ferrovias, dificultava a obtenção de cambiais ao pagamento de empréstimos externos e fazia com que os trabalhadores reivindicassem aumentos salariais para compensar a elevação no custo de vida (Saes, 2010; Souza, 1968; Ipeadata, 2019; Franco e Lago, 2012).

A Primeira República testemunharia o apogeu do conservadorismo monetário que ficaria associado a homens como Rodrigues Alves, Joaquim Murtinho e Leopoldo Bulhões, entre muitos outros, talvez na razão inversa dos excessos dos primeiros anos da República [...] (Franco e Lago, 2012, p. 179).

A assunção de Floriano à presidência da República e sua aliança com os PRP permitiu uma drástica mudança nos rumos da política monetária brasileira que, segundo Schulz (2013, p. 193) pode ser chamada de reação ortodoxa. O novo ministro da Fazenda era Francisco de Paula Rodrigues Alves, que recebera convite para se filiar ao PRP logo após o 15 de novembro de 1889, elegeu-se deputado constituinte pelo partido e, na Câmara, tornou-se presidente da Comissão de Orçamento. Seu nome foi endossado ao cargo pelas mais importantes figuras do PRP, como Campos Sales, Bernardino de Campos e Prudente de Moraes (Saes, 2010; Franco, 2000).

No Relatório do Ministério da Fazenda para o ano de 1892, elaborado sob a gestão de Rodrigues Alves, podemos perceber seu diagnóstico sobre as causas dos males econômicos que afligiam o Brasil e as medidas que saneariam as contas nacionais.

A fixidez e a valorização é, em matéria financeira, a principal questão de nosso país, como tendo sido em todas as nações que se viram obrigadas a lançar mão da moeda fiduciária. 
Dada a flutuação e depreciação do valor da moeda, todas as relações do crédito se alteram; a fortuna particular desce e sobe na frase dos economistas, como a coluna de mercúrio à ação da temperatura; as transações internacionais se perturbam; o capital estrangeiro deixa de afluir ao nosso mercado; finalmente, grandes quantias são destinadas no Orçamento ao pagamento de diferenças de câmbio pela passagem do numerário ao estrangeiro, a fim de ali serem satisfeitas as despesas com pessoal, compras de material e obrigações do Estado.

Entre nós, a depreciação da moeda nacional nunca atingiu aos limites destes últimos tempos.

Entre as causas a que geralmente se atribuem no país e no exterior às nossas dificuldades financeiras e econômicas, e sobretudo essa depreciação, é assinalada com insistência como a principal: o excesso das emissões bancárias, agravado pelas desconfianças de que não repousam em garantia e pelo receio de novas emissões (Fazenda, 1892, p. 24).

A visão da perniciosidade das emissões de papel-moeda no período recente está em consonância com as ideias ortodoxas defendidas pelas figuras representantes do metalismo na questão da política monetária nacional. Enquadrar Rodrigues Alves neste espectro do debate significa considerar sua trajetória pretérita que, mais do que opiniões sobre pensamento econômico, destaca-se pela defesa do conservadorismo em sua vasta atuação política, que iniciara como deputado provincial e o levara a comandar o estado de São Paulo por um breve período. Desde os bancos da Faculdade de Direito, ele sempre se posicionou no campo conservador que, trasladado ao embate sobre a moeda no Brasil no século XIX, significa que o político Rodrigues Alves, em matéria econômica, era um ortodoxo metalista.

Com tal visão, o plano de ação descrito no Relatório da Fazenda buscava restabelecer a ordem econômica nacional através da interrupção das emissões, começar o recolhimento do papel-moeda em excesso e negociar com os bancos a retomada pelo Tesouro do monopólio de emissão. Ademais, Rodrigues Alves visava reduzir as despesas públicas e aumentar as receitas, questionava a efetividade de recentes medidas econômicas, como os auxílios à lavoura indicando que estes créditos não chegavam aos fazendeiros mais necessitados e, também, de pleitos de grupos como os industriais que, dada a conjuntura do Encilhamento e retração de alguns bancos, alegavam uma falta de crédito e, por isso, buscavam um auxílio junto ao Governo Federal (Fazenda, 1892). 
As medidas para a interrupção das emissões e retirada do papel-moeda em circulação dependiam de aprovação na Câmara e no Senado, sendo que havia oposição dos senadores ao projeto de Rodrigues Alves. Por outro lado, a objeção do ministro aos auxílios financeiros demandados pelos industriais colocava-o em colisão, inclusive, com o presidente, que era tido como industrialista. Diante das dificuldades políticas para efetivação de suas medidas econômicas, a primeira passagem de Rodrigues Alves na pasta da Fazenda se veria abreviada, terminando após 9 meses no cargo quando, a 29 de agosto de 1892, ele apresentou sua demissão a Floriano Peixoto, sendo substituído pelo industrialista Serzedelo Corrêa (Franco, 2000). Sua saída desagradou os círculos mais conservadores da economia nacional, bem como os credores externos do Brasil - sobretudo os londrinos Rothschild - que viam nele a possibilidade do país retomar a austeridade financeira e, assim, manter-se no cumprimento das obrigações da dívida externa (Schulz, 2013)17.

"[O futuro presidente Afonso] Pena,

Recebi e agradeço sua carta. Não me foi possível continuar no ministério por falta de acordo com o chefe de Estado, principalmente na questão bancária. As minhas ideias combinam perfeitamente com as suas. Tive mesmo ensejo de referir-me, por mais de uma vez, à sua esclarecida opinião. $\mathrm{O}$ Marechal, porém, não compreende que haja vantagem em assumir o governo a responsabilidade pelas emissões bancárias e reputa essa providência radical e perigosa.

Compreende você que, estabelecido o desacordo em um ponto capital da administração da minha pasta, não me restava outro alvitre se não o de retirar-me.

Havia muito tempo eu insistira por uma solução. Consegui pôrme de acordo com as Comissões de Orçamento do Congresso. Ouvi a opinião dos nossos homens mais competentes. Apesar de tudo, as minhas ideias não alcançaram o apoio do chefe de Estado. Retirei-me. Não acha que não poderia proceder de outra forma?

Logo que tenha instalado os filhos no colégio, retirar-me-ei para São Paulo. Como sempre, amigo e colega" (Carta de Rodrigues Alves a Afonso Pena, a 20 de setembro de 1892 apud Franco, 2000, p. 186).

Após a demissão, Rodrigues Alves voltou para Guaratinguetá e ficou ausente de cargos políticos até março de 1893, mas manteve-se dentro da estrutura do PRP, em que ele se tornou presidente da Comissão Executiva,

17 "Em 29 de agosto este estadista, um daqueles a quem o Brasil deve os mais eminentes serviços pela sua reabilitação financeira, demitiu-se, com grande pesar para todo o comércio do Rio e para os círculos políticos conservadores, que viam, na sua administração e na sua política monetária, o melhor caminho para sair da trilha em que o haviam lançado os abusos de crédito de toda sorte" (Calógeras, 1960, p. 244). 
Revista Brasileira de História \& Ciências Sociais - RBHCS

Vol. 13 No 26, Janeiro - Junho de 2021

órgão que determinava os rumos do partido no nível estadual e nacional. Sua ascendência no partido fez com que lembrassem de seu nome para substituir e completar o mandato do senador paulista Rangel Pestana e, dessa forma, Rodrigues Alves foi eleito ao Senado Federal a 23 de março de 1893 - seria reeleito no ano seguinte para um mandato de nove anos (Love, 1982; Amaral e Franco, 2003).

No Senado, ele novamente presidiu a Comissão do Orçamento e, desta feita, em uma conjuntura econômica ainda mais aflitiva do que há 3 anos. Em 1893, o governo do marechal Floriano Peixoto encontrava-se enredado às intensas agitações da Revolução Federalista no Rio Grande do Sul (fevereiro de 1893-março de 1894) e da Revolta da Armada na Capital Federal (setembro de 1893-março de 1894). Os créditos extraordinários para manutenção das tropas assumiram preponderante peso no déficit do Orçamento Federal no biênio 1893-1894. Ademais, a necessidade de empréstimos em libras para compra de navios, munições e demais itens bélicos elevavam ainda mais os compromissos externos da economia brasileira (Schulz, 2013; Mattos, 2012).

Os gastos efetuados pelo Executivo de maneira extraordinária - inclusive os "auxílios à indústria" - dependiam de aprovação no Congresso que, por sua vez, tinha no PRP a principal força política. Os dirigentes do partido paulista, ao seu turno, viam no marechal Floriano um elemento de força que poderia debelar grupos opositores à sua futura ascensão política, como os deodoristas. Neste sentido, a aliança entre Floriano e os congressistas do PRP estabelece-se, cumprindo a função de dar votos à aprovação das demandas do presidente nas Casas Legislativas (Saes, 2010).

Esta aliança foi importante para consolidar o apoio de Floriano na eleição presidencial de março de 1894, em que Prudente de Moraes, candidato do PRP, ganhou o pleito e tornou-se o primeiro presidente civil do país (Souza, 1968). Ao assumir, no dia 15 de novembro daquele ano, Prudente materializaria a chegada do PRP no comando do aparelho de Estado Federal e traria com ele republicanos experientes, como Rodrigues Alves designado para o Ministério da Fazenda (Saes, 2010; Franco, 2000). Segundo Franco e Lago (2012, p. 187) este 
ato era "[...] uma nomeação que confirmava simultânea e paradoxalmente a predominância da oligarquia cafeeira e a ortodoxia metalista" 18 .

No Relatório do Ministério da Fazenda apresentado por Rodrigues Alves no começo de 1895 há um diagnóstico sobre a gravidade da crise econômica atravessada pelo país naquele momento. Primeiro, com os combates da Revolução Federalista somados à Revolta da Armada, o Orçamento Federal tornara-se uma peça fictícia, pois os conflitos faziam com que houvessem créditos extraordinários que implicavam em elevados déficits ao final do exercício fiscal. Este problema interno da escassez de receitas frente às despesas vultosas imbricava-se aos compromissos externos da economia brasileira, por exemplo, quando Rodrigues Alves aponta que a 14 de novembro de 1894 - um dia antes da posse do novo presidente - o marechal Floriano autorizou a celebração de um contrato para construção de navios de guerra à marinha brasileira em estaleiros franceses, o que contribuiu para que a dívida externa brasileira saltasse de 160 milhões de dólares no ano de 1894 para a cifra de 193,5 milhões no ano seguinte (Fazenda, 1895).

Com um Governo Federal incorrendo em gastos excessivos e vendo-se com dificuldades para honrar os compromissos externos, a taxa de câmbio seguia como um termômetro da crise, posto que, em 1890 ela estava cotada a 22 pence por mil réis e, em 1894, a cotação média anual foi de 10 pence por mil réis. Para Rodrigues Alves, a depreciação do câmbio maculava duplamente a economia nacional: externamente, ela afetava a confiança dos credores tradicionais do Brasil e alijava o país da rota dos grandes empréstimos; internamente, dado o elevado grau de importação do sistema econômico nacional - de bens simples como trigo às peças para ferrovias - um mil-réis desvalorizado traduzia-se em aumento no preço dos produtos, denominado à época como carestia e, atualmente, como inflação, que teria sido de $20 \%$ ao ano entre 1889-1894 (Fazenda, 1895; Franco e Lago, 2012).

18 É preciso mencionar que, apesar da reação conservadora do Estado brasileiro no campo econômico, com um ideário menos intervencionista em relação ao período de Rui Barbosa (1890-1891), os policy makers da Primeira República valeram-se de fortes instrumentos de intervenção para núcleos da elite econômica nacional, por exemplo, através do Plano de Valorização do Café (1906), que teve participação do Governo Federal na tomada de empréstimos no exterior às compras das sacas que seriam retiradas do mercado e vendidas futuramente. Dessa forma, mesmo que se possa considerar o liberalismo como ideologia dominante nos agentes políticos republicanos, houve momentos em que o pragmatismo os conduziu à intervenção econômica (Topik, 1987). 
Para Rodrigues Alves, estes eram os sintomas da crise e, deveria pontuarse, eles não provinham do lado produtivo da economia - o Brasil era o maior exportador mundial de café e borracha e a balança comercial não foi deficitária em nenhum ano do período 1894-1896 (Fazenda, 1895). O Ministro, no Relatório da Fazenda apresentado no começo de 1896, aponta de maneira contundente que a crise era financeira e sua raiz se encontrava nos excessos de emissão de moeda do Encilhamento.

Cumpre, porém, reconhecer que as mais acentuadas perturbações provém dos erros graves que se cometeram em relação às emissões bancárias, realizadas em 1890 e 1891.

Como sempre acontece quando se dão grandes emissões, ou desde que são autorizadas, o espírito de especulação bolsista e de lançamento de empresas ressurge com maior ou menor intensidade.

A enorme massa de bilhetes bancários atirados à circulação em pouco mais de um ano, facilitando o crédito de maneira incrível, produziu os funestos efeitos que se podiam prever, dando lugar a inúmeras criações de empresas cujo fim era fornecer títulos para o desenfreado jogo de Bolsa, consumindo colossais quantias fornecidas pelos bancos.

As empresas soçobraram em sua maior parte ou na quase totalidade, e os poderes públicos tiveram de pôr cobro à faculdade de emitir notas, tão desastrosamente utilizadas pelos institutos que a possuíam.

Infelizmente, os males produzidos não limitaram-se ao desastre das empresas loucamente planejadas, mas afetaram profundamente a vida da nação pelo influxo que as emissões exerceram no preço de todas as coisas, perturbando as relações do comércio interno e externo pela enorme baixa que determinaram no câmbio.

Pode-se afirmar que o mal estar geral do país provém principalmente dessa causa (Fazenda, 1896, p. 22-23).

A descrição minuciosa que Rodrigues Alves faz acerca das origens da crise financeira do Brasil em meados da primeira década republicana nos possibilita retomar qual era o seu ideário de política econômica dentro da querela entre metalistas e papelistas. Como Mollo e Fonseca (2012) indicaram, os ortodoxos metalistas viam a taxa de câmbio como um barômetro a indicar a pressão da economia nacional e advogavam que o câmbio valorizado - preferencialmente ao par com cotação oficial - levava ao aumento do grau de confiança dos agentes externos à economia, portanto, fazendo expandir os investimentos estrangeiros no país - resolvendo a escassez de divisas - e, concomitantemente, servindo como uma trava aos arroubos emissionistas do Governo, o que 
debelava o problema da carestia/inflação e dava previsibilidade aos agentes econômicos internos que, dessa forma, aumentavam seus investimentos.

O ideário de Rodrigues Alves no campo econômico é trazido da seara política, o de um conservador na acepção da palavra que, em assuntos econômicos, é exprimido na figura de um ortodoxo convicto (Franco e Lago, 2012). Esta imagem do ministro era importante para que lhe permitisse um grau de abertura com os credores externos, pois, logo no início de 1895, vários contratos em nome do Brasil venceriam no mercado europeu, sobretudo em Londres. Dessa forma, sua primeira ação no Ministério foi buscar tratativas com os Rothschild \& Sons para um empréstimo de 2 milhões de libras esterlinas ainda em janeiro de 1895, seguido de um grande empréstimo de 7,5 milhões de libras, lançado em Londres a julho daquele ano, cujos fundos levantados podem ser considerados um dos maiores sucessos de Rodrigues Alves na pasta da Fazenda (Franco, 1989) ${ }^{19}$.

Resolvidas as questões mais prementes do serviço da dívida externa, o ministro voltava suas atenções a aspectos que foram inclusive lembrados pelos credores ingleses: a necessidade orçamentária de diminuir despesas e aumentar receitas, bem como, de restabelecer a confiança na economia nacional através do resgate de papel-moeda. Sobre o orçamento para 1896, Rodrigues Alves indicava um plano contracionista que, do lado da despesa, apresentaria o governo federal diminuindo provisões militares - dado que a Revolta da Armada e a Revolução Federalista já haviam findado -, interromper temporariamente os projetos de extensão da malha ferroviária. Pelo lado da receita, ele postulava aumentar a arrecadação cobrando parte dos impostos de importação "em ouro", sugerindo uma alíquota de 30\% (Fazenda, 1896)²0.

19 O mercado de crédito encontrava-se em situação instável na Europa e Estados Unidos na
metade da década de 1890 e a crise do Banco Baring ainda afetava a tomada de empréstimos
pelos países da América Latina (Schulz, 2013, p. 210). O empréstimo de 7,5 milhões de libras
obtido pelo governo brasileiro teve papel fundamental dos Rothschild que, sobre a operação, diz
tratar-se de "[...] uma 'tarefa hercúlea' que resultou em 'tensionar cada nervo (straining every
nerve) dos mercados aqui e no continente" (Franco, 1989, p. 26).
20 Segundo Villela (2005, p. 42) "A cobrança de parte dos direitos 'em ouro' implicava que, ao
invés de se pagar $T$ réis por unidade do produto importado, pagava-se $(1-r) t+r$ x $t$ x $27 / E$,
onde $r$ é a proporção dos direitos a ser paga em ouro, $t$ são os direitos (fixos, isto é, em mil-réis)
especificados pela Tarifa em vigor e $E$ a taxa de câmbio (em pence por mil-réis). Disto resulta
que, a menos de a taxa de câmbio situar-se ao par (isto é, 27 d/1 $\$$ ooo), $T$ e $t$ divergirão, ou seja,
os direitos a serem pagos efetivamente não coincidirão com aqueles especificados na Tarifa. Um
exemplo ajuda a tornar mais claros os efeitos da tarifa-ouro: suponha-se um artigo cujo valor
oficial seja de $10 \$ 000$, sobre o qual a Tarifa especifica que devem incidir direitos de $1 \$$ ooo. 
Em relação ao excesso de papel-moeda, desde sua primeira passagem na Fazenda em 1891-1892, ela nutria a ideia de executar um grande plano de resgate junto aos bancos que, para tanto, deveriam entregar aos cofres do governo federal o total de papel-moeda bancário emitido, acrescido dos respectivos lastros, restando ao governo substituir este papel emitido por papelmoeda do Tesouro. Naquele momento, a circulação monetária que, em 1889 estava na casa de 200 mil contos de réis, já alcançara o patamar de $712 \mathrm{mil}$ contos réis, sendo que, aproximadamente metade deste valor era das emissões levadas pelos bancos. A contenda se encontrava justamente nos valores demandados por cada uma das partes, pois o governo federal cobrava os bancos emissionistas pelos empréstimos que eles tomaram junto ao Tesouro para formar seus respectivos lastros - por exemplo, em apólices da dívida pública. Todavia, os bancos alegavam que eles deveriam ser indenizados pelo Governo, pois os contratos estabelecidos previam um direito de emissão de moeda que se estenderia, como no caso do Banco União de São Paulo, por até 46 anos (Calógeras, 1960; Franco e Lago, 2012).

Os planos contracionistas de Rodrigues Alves, por melhor formulados que tenham sido, esbarraram na realidade da política, a qual ele tão bem conhecia. O Congresso não aprovou a cobrança de parte dos impostos em ouro e o projeto de encampação das emissões monetárias ficou travado nas discussões das duas Casas Legislativas. Uma medida paliativa para resgate do papel-moeda foi o lançamento de um empréstimo interno baseado em apólices da dívida pública, na primeira metade de 1895, e que levantou 30 mil contos de réis, dos quais 20 mil contos foram destinados a diminuir a circulação monetária (Calógeras, 1960; Franco, 2000).

O segundo semestre de 1896 apresentava um país tomado pela crise econômica que, a partir deste ponto, tinha no balanço de pagamentos o principal algoz (Schulz, 2013). As receitas de exportação do café diminuíram de 22,3 milhões de libras em 1895 para 19,6 milhões de libras em 1896, reflexo do acúmulo de estoques no mercado mundial cafeeiro. O saldo do balanço de

Neste caso, a razão correspondente é de $10 \%$ (1\$00o/10\$0oo). Agora, suponha adicionalmente que a legislação estabelecesse que 50\% dos direitos deveriam ser pagos "em ouro" e que a taxa de câmbio se encontrasse em 2od. Na prática, o importador desta mercadoria teria que desembolsar $0,5 \times 1.000+0,5 \times 1.000 \times 27 / 20=1.175$, isto é, $\$ 175$ réis a mais do que o originalmente previsto. Esta diferença correspondia ao chamado "ágio do ouro" e resultava do fato de a taxa de câmbio encontrar-se em 20d/1\$ooo, abaixo do par, portanto". 
pagamento, que havia sido de 5 milhões de libras esterlinas em 1895, caiu drasticamente para 30 mil libras em 1896, gerando tensão entre os credores externos sobre as condições de solvência da economia brasileira e, eventualmente, uma moratória da dívida externa - que não aconteceu (Ipeadata, 2019).

A taxa de câmbio, que era o termômetro de uma economia nacional na visão ortodoxo metalista, caiu ainda mais entre 1895-1896, passando de 9,9 pence por mil réis para 9,0 pence. A solução seria um grande empréstimo para consolidar a dívida externa, alongando-a e dando alívio de alguns anos ao orçamento federal no que tangia ao serviço da dívida. Mas, este esquema viria só em 1898, com o Funding Loan estabelecido no governo do presidente Campos Sales e seu ministro Joaquim Murtinho, quando Rodrigues Alves voltara ao cargo de senador federal por São Paulo, após ser removido do Ministério da Fazenda em novembro de 1896, momento em que o vicepresidente Manuel Vitorino assumiu o posto devido à problemas de saúde de Prudente de Moraes.

\section{Considerações Finais}

O ideário conservador de Rodrigues Alves, trazido de sua ação na política, o situava no campo metalista, condenando os excessos de emissão monetária do Encilhamento (1890-1891), traduzidos na figura de seu colega de bancos acadêmicos Rui Barbosa.

Nos três Relatórios de sua gestão à frente do Ministério da Fazenda (1892, 1895 e 1896) há um diagnóstico claro de como resolver a crise econômica cujos principais sintomas eram a alta da inflação e a desvalorização cambial, imputados às desvairadas emissões de moeda do início da década de 1890 . Todavia, seus projetos mais importantes não obtiveram êxito imediato no Congresso: o acordo entre Tesouro e bancos para resgate do papel-moeda não foi adiante, bem como o Congresso não aprovou a cobrança de parte dos impostos em ouro, medidas que possibilitariam a valorização cambial e o aumento nas Receitas Governamentais.

De outra parte, Rodrigues Alves, em uma seara mais afeita ao conservadorismo econômico, ele conseguiu lograr êxito junto aos credores externos que viabilizaram dois grandes empréstimos ao governo brasileiro no 
ano de 1895 que, somados, chegaram a quase 10 milhões de libras esterlinas, corroborando a visão positiva que círculos financeiros ortodoxos tinham de Rodrigues Alves no Brasil e, sobretudo, no exterior.

Estas duas experiências de Rodrigues Alves no Ministério da Fazenda ilustram um ponto que Calógeras (1960) apresenta no início de seu trabalho: os limites da ação econômica no campo da política. Tais limites puderam ser extravasados no bom relacionamento que Rodrigues Alves mantinha com o financistas internacionais, que envergavam como um fiador das políticas corretas, tidas como ortodoxas. Porém, as barreiras políticas internas às suas ações econômicas explicam o fracasso na tentativa, por exemplo, de aumentar a cobrança de impostos, medida que poderia ferir interesse de vários agentes econômicos relevantes.

O balanço a ser feito destas duas experiências deve levar em consideração a gravidade do quadro político e econômico do início da República. Se, de uma parte, a crise econômica não foi debelada ${ }^{21}$, porém, Rodrigues Alves teve o mérito de tentar solucionar os problemas, formular respostas e apontar o caminho das finanças saudáveis, traços que seriam valorizados pelo próprio mundo político e a população como um todo, afinal, ele seria eleito duas vezes para a presidência da República (1902 e 1818).

\section{Referências Bibliográficas}

ALMEIDA, I. C. S. e CROCE, M. Abolição, encilhamento e mercado financeiro: uma análise da primeira crise financeira republicana. Rev. Econ. do CentroOeste, Goiânia, v.2, n.2, pp.19-36, 2016.

AMARAL, M. T. e FRANCO, A. A. M. A vida dos grandes brasileiros: Rodrigues Alves. São Paulo: Editora Três, 2003.

BOBBIO, N., MATTEUCCI, N. e PASQUINO, G. Dicionário de Política. Brasília: Editora Universidade de Brasília, 1 ed., 1998.

CALÓGERAS, J. P. A política monetária do Brasil. São Paulo: Cia. Editora Nacional, 1960.

CARVALHO, J. M. A construção da ordem: a elite política imperial; Teatro de sombras: a política imperial. 3. ed. Rio de Janeiro: Civilização Brasileira, 2007.

${ }^{21}$ Eugênio Gudin (1972, p. 78) assim descreve a passagem de Rodrigues Alves no Ministério da Fazenda: "No quatriênio Prudente de Moraes, avassalado pelos problemas políticos e pelas consequências da Guerra Civil de 1893/94, pouco se pôde fazer para melhoria da situação. Contudo o alto critério de Ministros da Fazenda como Rodrigues Alves e Bernardino de Campos, permitiu que, apesar de todas as dificuldades, a situação não piorasse". 
Revista Brasileira de História \& Ciências Sociais - RBHCS

Vol. 13 No 26, Janeiro - Junho de 2021

COLISTETE, R. P. Iniciativas locais e mobilização por escolas primárias em São Paulo, 1830-1889. Revista de História, v. 176, p. 1-37, 2017.

COSTA, E. V. Da senzala à colônia. São Paulo: Livraria Editora da UNESP, 1998.

EICHENGREEN, B. A globalização do capital. São Paulo: Editora 34, 2000.

FAORO, R. Rodrigues Alves: o enigma decifrado? In: FRANCO, A. A. M. Rodrigues Alves: apogeu e declínio do presidencialismo. Brasília: Senado Federal, Conselho Editorial, 2000.

FAZENDA. Relatório apresentado ao vice-presidente da República dos Estados Unidos do Brasil pelo ministro de Estado dos Negócios da Fazenda Francisco de Paula Rodrigues Alves no ano de 1892. Rio de Janeiro: Imprensa Nacional, 1892.

FAZENDA. Relatório apresentado ao presidente da República dos Estados Unidos do Brasil pelo ministro de Estado dos Negócios da Fazenda Francisco de Paula Rodrigues Alves no ano de 1895. Rio de Janeiro: Imprensa Nacional, 1895 .

FAZENDA. Relatório apresentado ao presidente da República dos Estados Unidos do Brasil pelo ministro de Estado dos Negócios da Fazenda Francisco de Paula Rodrigues Alves no ano de 1896. Rio de Janeiro: Imprensa Nacional, 1896.

FERRARO, A. R. e KREIDLOW, D. Analfabetismo no Brasil: configuração e gênese das desigualdades regionais. Educação \& realidade. Porto Alegre. Vol. 29, n. 2 (jul./dez. 2004), p. 179-200.

FISHLOW, A. Origens e consequências da substituição de importação no Brasil. Estudos Econômicos. v.2, n.6, dez.1972:7-76.

FONSECA, P. C. D.; MOLLO, M. L. R. Metalistas e Papelistas no Brasil: origens teóricas e antecedentes do debate entre monetaristas e estruturalistas no Brasil. Nova Economia, vol. 22 (2), maio/ago. 2012, p. 203-233.

FRANCO, A. A. M. Rodrigues Alves: apogeu e declínio do presidencialismo. Brasília: Senado Federal, Conselho Editorial, 2000.

FRANCO, G. H. B. A primeira década republicana. In: ABREU, M. P. (org.). A Ordem do Progresso: cem anos de política econômica republicana, 1889-1989. Rio de Janeiro: Campus, 1989.

FRANCO, G. H. B. O balanço de pagamentos do Brasil, 1870-19oo. Rio de Janeiro: PUC, 1988. (Departamento de Economia. Texto para discussão, 201).

FRANCO, G. H. B. e LAGO, L. A. C. “O processo econômico”. In: SCHWARCZ, L. M. A abertura para o mundo: 1889-1930. Rio de Janeiro: Objetiva, 2012.

FURTADO, C. Formação Econômica do Brasil. São Paulo: Companhia Editora Nacional, 2000.

GUDIN, E. Notas sobre a Economia Brasileira desde a Proclamação da República até os nossos dias. Revista Brasileira de Economia, vol. 26, n. 03, julho/setembro de 1972, Rio de Janeiro: FGV.

HOLANDA, S. B. O Brasil Monárquico, v. 7: do Império à República (História Geral da Civilização Brasileira; t. 2; v. 7). Rio de Janeiro: Bertrand Brasil, 2008. 
Revista Brasileira de História \& Ciências Sociais - RBHCS

Vol. 13 No 26, Janeiro - Junho de 2021

IPEADATA. Instituto de Pesquisa Econômica Aplicada: Dados macroeconômicos. Disponível em: http://www.ipeadata.gov.br/Default.aspx Acesso em fev. 2019.

KUGELMAS, E. A difícil hegemonia. São Paulo: FFLCH/USP, tese de doutoramento, 1986.

LANG, A. B. S. G. Rodrigues Alves: Verbete. In: ABREU, A. A. A. Dicionário histórico-biográfico da Primeira República 1889-1930. Rio de Janeiro: Fundação Getúlio Vargas, 2016, acesso em 20/02/2019 https://atlas.fgv.br/verbetes/rodrigues-alves

LENZ, M. H. A crise argentina de 1890: dívida e instabilidade externa. Análise Econômica, Porto Alegre, ano 28, n. 54, p. 225-248, set. 2010.

LEVY, M. B. História da Bolsa de Valores do Rio de Janeiro. Rio de Janeiro, RJ: IBMEC, 1977.

LEVY, M. B. A indústria do Rio de Janeiro através de suas sociedades anônimas. Rio de Janeiro: Editora UFRJ; Secretaria Municipal de Cultura do Rio de Janeiro, 1994.

LOBO, M. E. L. O Encilhamento. Revista Brasileira do Mercado de Capitais, Rio de Janeiro, vol. 2, n. 5, mai-ago 1976.

LOVE, J. A Locomotiva: São Paulo na Federação Brasileira 1889-1937. Rio de Janeiro: Paz e Terra, 1982.

LUNA, F. V.; KLEIN, H. S. Evolução da sociedade e economia escravista de São Paulo, de 1750 a 1850. São Paulo: Editora da Universidade de São Paulo, 2005.

MARCONDES, R. L. e HANLEY, A. G. Bancos na transição republicana em São Paulo: o financiamento hipotecário (1888-1901). Estud. Econ., São Paulo, v. 40, n. 1, Mar. 2010.

MATTOS, H. "A vida política”. In: SCHWARCZ, L. M. A abertura para o mundo: 1889-1930. Rio de Janeiro: Objetiva, 2012.

MOURA, C. E. M. O Visconde de Guaratinguetá: um fazendeiro de café no Vale do Paraíba. São Paulo: Studio Nobel, 2002.

QUEIROZ, M. I. P. "O coronelismo numa interpretação sociológica". In: FAUSTO, B. História Geral da Civilização Brasileira. Tomo III (4v.). O Brasil Republicano, $1^{\mathrm{O}}$ volume: Estrutura de Poder e Economia (1889-1930). Rio de Janeiro: Bertrand Brasil, 2006.

RICARDO, C. Centenário do Conselheiro Rodrigues Alves. São Paulo: Editora Revista dos Tribunais, 1951.

ROCHA, I. P. Imigração internacional em São Paulo: retorno e reemigração, 1890-1920. 2007. Dissertação (Mestrado em História Econômica) - Faculdade de Filosofia, Letras e Ciências Humanas, Universidade de São Paulo, São Paulo, 2007.

SAES, G. A. M. O Partido Republicano Paulista e a luta pela hegemonia política (1889-1898). In: ODALIA, N. e CALDEIRA, J. R. C. História do estado de São Paulo: a formação da unidade paulista: São Paulo: Editora Unesp; Imprensa Oficial; APESP, 2010. 
SALLES, R. As águas do Niágara. 1871: crise da escravidão e o ocaso saquarema. In: GRINBERG, K.; SALLES, R. (org.). O Brasil imperial, volume II: 1879-1889. Rio de Janeiro: Civilização Brasileira, 2009.

SANTOS, L. F. M. A atuação da Burschenschaft na política brasileira durante a Primeira República. IX Simpósio Regional de História, 2000.

SÃO PAULO. Relatório apresentado à Assembleia Legislativa Provincial de São Paulo pelo Presidente da Província Exm. Snr. Dr. Francisco de Paula Rodrigues Alves a 10 de janeiro de 1888. São Paulo: Typographia a vapor de Jorge Seckler \& Comp., 1888a.

SÃO PAULO. Relatório com que o Exm Snr. Dr. Francisco de Paula Rodrigues Alves passou a administração da Província de São Paulo ao Exm. Snr. Dr. Francisco Ant4onio Dutra Rodrigues a 27 de abril de 1888. São Paulo: Typographia a vapor de Jorge Seckler \& Comp., 1888b.

SCHULZ, J. A crise financeira da Abolição. São Paulo: Ed. USP, 2013.

SILVA, Gastão Pereira da. Rodrigues Alves e Sua Época. São Paulo: Ed. A Noite, 1939.

SINGER, P. O Brasil no contexto do capitalismo internacional: 1889-1930. In: FAUSTO, B. História Geral da Civilização Brasileira. Tomo III (4v.). Estrutura de Poder e Economia (1889-1930). Rio de Janeiro: Bertrand Brasil, 2006.

SOUZA, M. C. C. O processo político-partidário na primeira república. In: MOTA, C. G. Brasil em perspectiva. São Paulo: Difel; 1968.

STEIN, S. J. Origens e evolução da indústria têxtil no Brasil, 1850-1950. Rio de Janeiro: Campus, 1979.

SUZIGAN, W. Indústria Brasileira: origem e desenvolvimento. São Paulo: Ed. Hucitec/ Ed. Unicamp, 2000.

TANNURI, L. A. O encilhamento. São Paulo, SP: Hucitec, 1981.

TAUNAY, A. E. O encilhamento: cenas contemporâneas da Bolsa do Rio de Janeiro em 189o, 1891 e 1892. São Paulo, SP: Melhoramentos, 1923.

TOPIK, S. A presença do estado na economia política do Brasil de 1889 a 1930. São Paulo: Record, 1987.

TRINER, G. British Banking in Brazil during the First Republic. Locus, Juiz de Fora, v. 20, n. 2, p. 153-175, 2014.

TRINER, G., e WANDSCHNEIDER, K. The Baring Crisis and the Brazilian Encilhamento, 1889-1891: An Early Example of Contagion Among Emerging Capital Markets. Financial History Review, 12(2), 199-225, 2005.

VERSIANI, F. R. Industrialização e economia de exportação: a experiência brasileira antes de 1914. Rev. bras. Econ., Rio de Janeiro, 34 (1): 3-40, jan./mar. 1980.

VILLELA, A. A. Política tarifária no II Reinado: evolução e impactos, 18501889. Nova Economia. Belo Horizonte, v.15, n. 1, p. 35-68, jan/abr, 2005. 